\title{
Recent developments on nanostructured polymer-based membranes
}

Witopo Salim ${ }^{1}$ and W.S. Winston $\mathrm{Ho}^{1,2}$

Addresses:

${ }^{1}$ William G. Lowrie Department of Chemical and Biomolecular Engineering, The Ohio State University, 151 West Woodruff Avenue, Columbus, OH 43210-1350, USA

${ }^{2}$ Department of Materials Science and Engineering, The Ohio State University, 2041 College Road, Columbus, OH 43210-1178, USA

Corresponding author: W.S. Winston Ho (Email: ho.192@osu.edu, Phone: +1-614-2929970, Fax: +1-614-292-3769) 


\section{Abstract}

Advances in nanotechnology in recent years enhance the R\&D in nanostructured membranes. This paper reviews the recent developments of the nanostructured polymer-based membranes, formed by incorporating nanomaterials and/or porous membranes with nanoscale pores, for gas separations, reverse osmosis, ultrafiltration, and other potential applications. Significant progress has been made on the development of nanostructured membranes for gas separations, particularly for $\mathrm{CO}_{2}$ separations from $\mathrm{H}_{2}, \mathrm{~N}_{2}$ and $\mathrm{CH}_{4}$. Continued improvements on the nanostructured reverse osmosis polyamide membranes via interfacial polymerization have been made along with the efforts on developing novel nanostructured membranes for desalination. The modification of both the surface and bulk properties of the ultrafiltration membranes by nanomaterials can improve the membrane performance and open up the possibility of new applications in addition to those for the current ultrafiltration membrane processes. 


\section{Introduction}

According to the International Organization for Standardization (ISO) [1], nanostructured material is defined as "material having internal nanostructure or surface nanostructure", where nanostructure is defined as "composition of inter-related constituent parts, in which one or more of those parts is a nanoscale region" and nanoscale is defined as "size range from approximately $1 \mathrm{~nm}$ to $100 \mathrm{~nm}$ ". Based on the definitions, nanostructured membranes can be defined as membranes having internal or surface nanostructure $\left[2^{\bullet}\right]$. The nanostructured membrane can be a dense membrane incorporated with nanomaterials, a porous membrane with nanoscale pores, or a combination of both, as illustrated in Figure 1.

In this review, the recent developments of nanostructured membranes in different applications are covered, including gas separations, reverse osmosis, ultrafiltration, and several other applications including controlled release, antibiotic recovery (e.g., Cephalexin), and nanoporous supports for gas separation. Polymer-based membranes will be emphasized in view of availability, price, and ease of scale-up and commercialization.

\section{Nanostructured Membranes for Gas Separations}

Various nanomaterials have been incorporated into polymer matrixes to prepare nanostructured membranes for gas separations, including titanium dioxide $\left(\mathrm{TiO}_{2}\right)$, silica $\left(\mathrm{SiO}_{2}\right)$, carbon nanotubes, zeolite, and metal organic frameworks (MOF). The selection of the nanomaterial and polymer matrix has been the subject of extensive research recently [3-18]. Titanium dioxide was favored due to its hydrophilicity, chemical and thermal stability, and gas separation properties [3-5]. Up to $10 \mathrm{wt} \%$ of fumed $\mathrm{TiO}_{2}$ nanoparticles (size of $21 \mathrm{~nm}$ ) was homogeneously dispersed 
in polyvinylacetate membranes [6]. Addition of $1-10 \mathrm{wt} \%$ of $\mathrm{TiO}_{2}$ improved both the permeability and selectivity of the nanocomposite membranes.

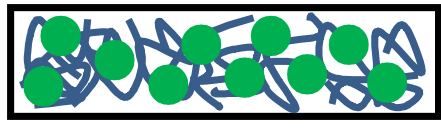

(a)

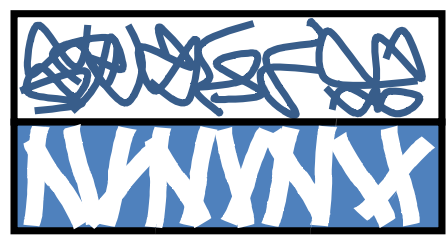

(c)

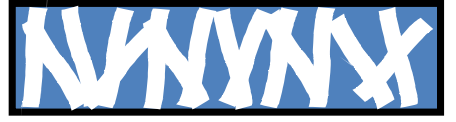

(b)

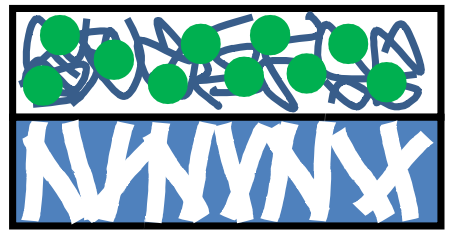

(d)

Nanoparticles $\vec{\sim}$ Polymer chains $\|$ Nanoscale pores

Figure 1. Schematics of nanostructured membranes: (a) Dense membrane incorporated with nanomaterials, i.e., nanoparticles, (b) Porous membrane with nanoscale pores, (c) Dense membrane on a porous membrane with nanoscale pores, and (d) Dense membrane incorporated with nanomaterials, i.e., nanoparticles, on a porous membrane with nanoscale pores.

Silica can enhance the thermal and mechanical stabilities as well as the gas separation property of membranes [7-9]. Xing and Ho [10] incorporated fumed silica nanoparticles (FS) with a size of $7 \mathrm{~nm}$ into crosslinked poly(vinyl alcohol)-poly(siloxane) membrane matrixes for highpressure $\mathrm{CO}_{2} / \mathrm{H}_{2}$ separation. They obtained the best performance with a $\mathrm{CO}_{2} / \mathrm{H}_{2}$ selectivity of 87 
and a $\mathrm{CO}_{2}$ permeability of 1296 Barrers $\left(1\right.$ Barrer $=10^{-10} \mathrm{~cm}^{3}(\mathrm{STP}) \mathrm{cm} /\left(\mathrm{cm}^{2} \mathrm{~s} \mathrm{cmHg}\right)=3.35 \mathrm{x}$ $\left.10^{-16} \mathrm{~mol} \mathrm{~m} /\left(\mathrm{m}^{2} \mathrm{~s} \mathrm{~Pa}\right)\right)$ at $107^{\circ} \mathrm{C}$ and 220 psia with $22.3 \mathrm{wt} \% \mathrm{FS}$ loading in the membrane.

Carbon nanotubes have excellent mechanical and thermal stabilities and potential to minimize the compaction effect in high-pressure gas separation [11,12]. Deng and Hägg [13] reinforced polyvinylamine/polyvinylalcohol blend membrane with $1 \mathrm{wt} \%$ of carbon nanotubes (CNTs, $1-2$ $\mu \mathrm{m}$ in length and $20-80 \mathrm{~nm}$ in diameter) for $\mathrm{CO}_{2} / \mathrm{CH}_{4}$ separation. The CNTs were compatible with the blend polymer membrane and enhanced the water swelling, performance, and durability against the compaction effect at elevated pressures up to 15 bar $(1.5 \mathrm{MPa})$. Zhao et al. $\left[14^{\bullet \bullet}\right]$ utilized both untreated multi-walled carbon nanotubes (MWNTs, $10-15 \mathrm{~nm}$ in diameter and 0.1 $-10 \mu \mathrm{m}$ in length) and acid-treated multi-walled carbon nanotubes (AT-MWNTs) as mechanical reinforcing fillers in the crosslinked poly(vinyl alcohol)-poly(siloxane) membrane matrix for high-pressure $\mathrm{CO}_{2} / \mathrm{H}_{2}$ separation. During the first 18.5 days test at $1.52 \mathrm{MPa}$ and $380.15 \mathrm{~K}$, the membrane had no change of performance with a $\mathrm{CO}_{2}$ permeability of 836 Barrers and $\mathrm{CO}_{2} / \mathrm{H}_{2}$ selectivity of 43 . The improvement was attributed to the ability of MWNTs to improve the mechanical strength and anti-compaction property of the mixed matrix membranes. The optimum untreated MWNTs loading was $2 \mathrm{wt} \%$, and as the MWNTs increased further, the membrane performance reduced with time due to the poor dispersion of the MWNTs. However, the dispersion improved with AT-MWNTs. The membrane with $4 \mathrm{wt} \%$ of AT-MWNTs had a stable membrane performance with a $\mathrm{CO}_{2}$ permeability of 896 Barrers and a $\mathrm{CO}_{2} / \mathrm{H}_{2}$ selectivity of 50.9 for at least 11 days.

Graphene oxide has the potential in gas separation application once an ultra-thin $(1-10 \mathrm{~nm})$ of few layers of graphene is used [15-16]. Shen et al. [17] incorporated laminar structures of 
graphene oxide with a thickness of $6-15 \mathrm{~nm}$ into the polyether block amide (PEBA) matrix and reported a $\mathrm{CO}_{2}$ permeability of 100 Barrers and a $\mathrm{CO}_{2} / \mathrm{N}_{2}$ selectivity of 91 .

MOFs, which consist of metal ions and organic molecules in three-dimensional structures with high surface area and porosity that can be fine-tuned, have attracted interests from many researchers [18-20]. A dual layer (organic- and inorganic-based) was formed when the zeolitic imidazolate framework (ZIF)-8 with a pore size of $0.34 \mathrm{~nm}$ was used as an inorganic filler in the PEBAX-2533 polymer matrix [21]. As the loading of ZIF-8 increased, the inorganic-based layer thickness increased and hence the permeability was increased whereas the selectivity was constant or slightly reduced.

Polymers of intrinsic microporosity (PIMs) have been considered for gas separation application primarily due to its microporosity, which results in a high free volume [22-24]. One type of polymers of intrinsic microporosity (PIMs), PIM-1, has recently been blended with other components such as mesoporous chromium (III) terephthalate MIL-101 [22], polyetherimide [23], and porous aromatic framework PAF-1 [24] in order to improve the specific surface area, gas transport properties, and reduce the porosity loss (physical aging).

Many efforts were made recently to reduce the thickness of the membrane selective layer in order to improve the permeance of gas separation, and some researchers were getting close to the nanoscale range of membrane thickness [25-29]. Nanoporous ultrafiltration membranes were utilized as the supports for very thin selective layers to maintain a good mechanical property. Qiao et al. $\left[25^{\circ}\right]$ coated a thin layer of polyvinylamine/piperazine with a thickness as thin as 130 $\mathrm{nm}$ on a polysulfone ultrafiltration membrane. The membrane with $220 \mathrm{~nm}$ of thickness had a $\mathrm{CO}_{2}$ permeance of $2.18 \mu \mathrm{mol} /\left(\mathrm{m}^{2} \mathrm{~s} \mathrm{~Pa}\right)$ and a $\mathrm{CO}_{2} / \mathrm{N}_{2}$ selectivity of 277 at $22^{\circ} \mathrm{C}$ and $0.11 \mathrm{MPa}$. Ho and coworkers $\left[26^{\circ}\right]$ developed a novel inorganic/polymer composite membrane, consisting 
of a selective amine-containing polymer cover layer / a zeolite nanoparticle layer / a polymer support, for $\mathrm{CO}_{2}$ capture. Zeolite-Y nanoparticles with around $40 \mathrm{~nm}$ of diameter were synthesized with a rapid (1 hour) zeolite growth method [27] and then packed into a layer with a thickness of $250 \mathrm{~nm}$. A selective amine-containing polymer cover layer with a thickness of 200 $\mathrm{nm}$ was coated on the zeolite layer. They continuously fabricated a 14" wide of the inorganic/polymer composite membrane and rolled it into a spiral-wound module with a countercurrent configuration. The membrane showed great potential for the post-combustion $\mathrm{CO}_{2}$ capture from flue gas in coal-fired power plants [28].

Merkel and coworkers [29•• ] developed a $\mathrm{CO}_{2}$-selective membrane for $\mathrm{H}_{2}$ production and $\mathrm{CO}_{2}$ capture in three stages: laboratory tests $\left(\right.$ membrane area $=30 \mathrm{~cm}^{2}$ ), pilot-scale test with real syngas (membrane area $=1-4 \mathrm{~m}^{2}$ ), and membrane demonstration system (membrane area $=20$ $\mathrm{m}^{2}$ ) at the National Carbon Capture Center (NCCC) in Wilsonville, AL. The thin-film composite Polaris ${ }^{\mathrm{TM}}$ membranes consisted of around $50-200 \mathrm{~nm}$ of a $\mathrm{CO}_{2}$-selective layer on top of around $50-200 \mathrm{~nm}$ of a gutter layer, which were prepared by dip-coating on a nanoporous ultrafiltration support. The membrane demonstration system fed with $227 \mathrm{~kg} / \mathrm{h}$ of syngas with around $9 \%$ of $\mathrm{CO}_{2}$ produced a liquid $\mathrm{CO}_{2}$ product with $>95 \%$ of $\mathrm{CO}_{2}$.

\section{Nanostructured Membranes for Reverse Osmosis}

The commercial reverse osmosis membranes are based on a thin-film composite (TFC) of aromatic polyamide on a porous substrate layer prepared via interfacial polymerization, which was invented by Cadotte in 1981 [30]. Therefore, improvements on the state-of-the-art reverse osmosis membrane can be achieved either by improving the polyamide TFC layer or improving 
the porous substrate layer. The polyamide TFC layer can be improved by incorporation of additives $\left[31^{\bullet}\right]$ or incorporation of nanomaterials to form nano-enhanced membranes $\left[32^{\bullet}\right]$.

Zhao et al. [33,34] incorporated hydrophilic additives during the formation of polyamide membrane by interfacial polymerization on a nanoporous $(\sim 7 \mathrm{~nm})$ polysulfone substrate. They concluded that the hydrophilic additive of $o$-aminobenzoic acid-triethylamine (o-ABA-TEA) salt gave stable performance of a high water flux of $52.6 \mathrm{gfd}\left(1 \mathrm{gfd}=1 \mathrm{gal} /\left(\mathrm{ft}^{2}\right.\right.$ day $)=4.72 \times 10^{-7}$ $\left.\mathrm{m}^{3} /\left(\mathrm{m}^{2} \mathrm{~s}\right)\right)$ and a salt rejection of more than $98.8 \%$ under testing with brackish water desalination condition of $2000 \mathrm{ppm} \mathrm{NaCl}$ solution at $225 \mathrm{psi}$ and $25^{\circ} \mathrm{C}$ for at least 30 days. The fouling resistance of the membrane was improved by coating a crosslinked polyethylene glycol (PEG200) layer on top of the polyamide membrane. The membrane exhibited a salt rejection of $98.4 \%$ and a very high water flux of $60.4 \mathrm{gfd}$, which was more than twice of the water flux of the commercial FT-30 membrane. The membrane modified with the crosslinked-PEG had much less water flux reduction due to cationic surfactant (dodecyltrimethylammonium bromide) or organic foulant (tannic acid), which was attributed to the more hydrophilic and smoother surface of the modified membrane.

Zhao and Ho [35 $\left.{ }^{\bullet \bullet}\right]$ subsequently tested the high-flux membrane under seawater desalination conditions, both synthetic as well as real seawater from Port Hueneme, CA. The membrane gave a water flux of $44.4 \mathrm{gfd}$ and a salt rejection of $99.41 \%$ during the test with a synthetic $3.28 \mathrm{wt} \%$ $\mathrm{NaCl}$ solution at $800 \mathrm{psi}(5.52 \mathrm{MPa})$ and $25^{\circ} \mathrm{C}$. A stable but slightly lower water flux of $41.6 \mathrm{gfd}$ and a salt rejection of $99.4 \%$ were obtained during the 30 -day test with the real seawater from Port Hueneme, which was attributed to the higher $\mathrm{NaCl}$ content of $3.45 \mathrm{wt} \%$. In the presence of sodium alginate $(\mathrm{NaAlg})$, an organic foulant from seaweed, the high-flux membrane with the hydrophilic additive had a considerably less water flux reduction as compared to the basic 
membrane without the hydrophilic additive. It was believed that the negatively charged, hydrophilic groups provided by the hydrophilic additive as well as the improved smoothness of membrane surface were the causes of the improved fouling resistance of the high-flux membrane.

For reverse osmosis application, nanomaterials such as zeolites, carbon nanotubes, and graphene oxide are promising since they can be synthesized to have non-tortuous pores on the order of a few $\mathrm{nm}$ for the transport of water molecules in the desalination process [36-42]. Fathizadeh et al. [36] incorporated nano-NaX zeolite $(40-150 \mathrm{~nm})$ during the formation of polyamide membrane via interfacial polymerization. The nano-NaX zeolite increased the water flux by 1.8 times of the neat polyamide membrane without any change in the salt rejection. Pendergast et al. [37] used Linde Type A zeolite to prepare the polyamide membrane via interfacial polymerization on either a polysulfone or zeolite A-polysulfone nanocomposite support.

Advances in the carbon nanotube (CNT) synthesis enable the production of CNTs with a diameter as low as $1.6 \mathrm{~nm}\left[38^{\circ}\right]$, which makes it useful for the reverse osmosis application. Vertically aligned $[\mathrm{VA}]$ and mixed matrix membranes [MMM] containing carbon nanotubes are two types of membranes which have been explored recently [39 ${ }^{\circ}$. The VA-CNT membranes were prepared by aligning CNTs vertically with supportive fillers between the carbon nanotubes [40]. MMM-CNT membranes were synthesized by incorporating the CNTs into the polymer matrix [41].

Graphene oxide (GO) is a layer of graphite carbon, oxygen, and hydrogen in a thickness around an atom with tunable pore sizes that can be used as molecular sieves [38 ${ }^{\circ}$. Choi et al. [42] coated multilayers of graphene oxide via layer-by-layer deposition of oppositely charge GO 
nanosheets. They demonstrated an improvement on the reduction of salt rejection of the membrane upon exposure to chlorine due to the inert nature of the GO nanosheets.

Considerable efforts were put to develop a new membrane which could outperform the interfacially polymerized aromatic polyamide membranes. Inorganic zeolite membranes were studied including silicalite, ZSM-5, sodalite (SOD), and Linde Type A (LTA) zeolites [32]. Kim et al. [43] synthesized poly(arylene ether sulfone) containing functional zeolite nanoparticles and obtained a water flux of $22.3 \mathrm{gfd}$ and a salt rejection of $98.8 \%$. Akin et al. [44] synthesized the reduced graphene oxide/polyaniline composite dispersed in polysulfone prior to the phase inversion polymerization method. However, more research remains to be done before heading into commercialization of these novel membranes.

\section{Nanostructured Membranes for Ultrafiltration}

Ultrafiltration is a membrane-based separation process used in applications such as water treatment and the product separation in food, dairy, textile and chemical industries. Ultrafiltration membranes generally have pores in the nanoscale range of $1-100 \mathrm{~nm}$ and are prepared by the phase inversion method [45]. The most common way to create the pores in the phase inversion method is by immersion precipitation (also known as nonsolvent induced phase separation), in which a polymer solution cast on a support is immersed in a coagulation bath containing a nonsolvent. During the immersion step, an exchange of solvent and nonsolvent occurs and porous membranes are formed.

One of the recent advances in the preparation of ultrafiltration membranes is the incorporation of inorganic nanoparticles in order to improve the membrane properties such as mechanical strength, structure, hydrophilicity, and surface charge [46-57]. Poly(vinylidene fluoride) (PVDF) 
is the most popular polymer used in low-pressure ultrafiltration for water treatment application [46 ${ }^{\circ}$. Hong and $\mathrm{He}$ [47] incorporated $\mathrm{ZnO}$ nanoparticles into PVDF and reported that the membrane had a photo-catalysis self-cleaning capability. Jin et al. [48] compared the effects of different fillers (organic additives and nano- $\mathrm{TiO}_{2}$ ) on the performance of the PVDF membranes. $\mathrm{Yi}$ et al. [49] estimated the fouling stages of $\mathrm{Al}_{2} \mathrm{O}_{3} / \mathrm{TiO}_{2}$ nanoparticles-modified PVDF membranes in oil/water emulsion separation.

Polysulfone (PSf) is often selected due to its availability commercially, fluid transport properties, ease of processing, and thermal stability $\left[50^{\circ}\right]$. Alhoshan et al. [51] revealed that the PSf membrane containing nano- $\mathrm{ZnO}$ had a hydrophilic, smooth, tightly packed surface and a spongy structure with well-interconnected pores. $\mathrm{Wu}$ et al. [52] incorporated silica-graphene oxide $\left(\mathrm{SiO}_{2}-\mathrm{GO}\right)$ nanohybrid into a PSf membrane and increased the water flux up to two times of the PSf membrane. Liu et al. [53] had a breakthrough on the tradeoff between permeability and selectivity of PSf membranes by embedding zeolite 4A, which regulated the morphology and provided nanoscale water flow channels as well as negatively charged membrane surfaces. Polyethersulfone (PES) is widely used due to its outstanding oxidative and thermal stabilities and mechanical property $\left[54^{\circ}\right]$. Lin et al. [55] embedded tungsten disulfide nanoparticles (nano$\mathrm{WS}_{2}$ ) into a PES membrane and improved the water permeability, solute rejection, and fouling resistance of the PES membrane. Kim et al. [56] compared two methods to incorporate $\mathrm{TiO}_{2}$ into a PES membrane, i.e., embedding $\mathrm{TiO}_{2}$ during phase inversion and surface coating by layer-bylayer deposition of $\mathrm{TiO}_{2}$. Akar et al. [57] investigated the characterization and biofouling properties of the PES membrane containing selenium (Se) and copper $(\mathrm{Cu})$ nanoparticles.

Other polymers (polyacrylonitrile, polyimides, polyamides, and polytetrafluoroethylene) can also be used to synthesize ultrafiltration membranes $\left[58^{\bullet}\right]$. The nanoscale range of ultrafiltration 
membranes is also attractive for applications outside of ultrafiltration. Researchers attempted to manipulate the pore size and porous structure of the membranes to suit the intended applications [59-67].

Yen et al. [59] varied the polymer concentration in the casting solution during the thermally- and nonsolvent-induced phase inversion steps and reduced the pore size from $90 \mathrm{~nm}$ to $55 \mathrm{~nm}$ to control the release of lysozyme at a constant rate. This poly(caprolactone) membrane showed potential as a controlled-release drug delivery device for biomedical application. They also investigated the effects of plasma power and treatment time [60] and the effects of graft density and chain length [61] on polyethyleneglycol grafting to prevent biofouling.

Vilt and Ho [62-64] used hollow fiber modules (Module G453 from Membrana) with a pore size of $0.03 \mu \mathrm{m}(30 \mathrm{~nm})$ and a porosity of around $40 \%$ as a support of the supported liquid membrane with strip dispersion (SLM-SD) to recover Cephalexin by using the carrier Aliquat 336 (QCl). The mass transfer resistances were analyzed, and the extraction reaction resistance was found dominant $(>90 \%)$. In situ removal and recovery of Cephalexin by SLM-SD following the enzymatic synthesis of Cephalexin by using two hollow-fiber modules in series was able to increase the Cephalexin yield from $32 \%$ to $42 \%$.

In order to minimize the extraction reaction resistance, Hao et al. $[65,66]$ proposed the supported liquid membranes with feed dispersion (SLM-FD) and organic dispersion (SLM-OD). The SLM-FD was prepared by dispersing the aqueous feed solution in the organic membrane phase, whereas SLM-OD was done by dispersing the organic membrane solution in the aqueous feed phase. The extraction reaction resistance in the SLM-FD as well as SLM-OD was greatly reduced due to a large mass transfer area formed by the dispersions. Moreover, the SLM-OD offered an advantage of the reduced organic membrane solution amount. 
Ho and coworkers [67] developed the continuous fabrication of 14-inch wide polyethersulfone (PES) supports with various pore sizes ranging from $40 \mathrm{~nm}$ to $90 \mathrm{~nm}$. The membrane with a pore size of $69.5 \mathrm{~nm}$ and a porosity of $16.9 \%$ was very similar to the commercial PES ultrafiltration membrane (pore size $=72.3 \mathrm{~nm}$, porosity $=15.8 \%$ ) used in protein purification. Alternatively, the membrane can also be used as a nanoporous support for a very thin selective layer for gas separation application since the nanoporous support will provide a negligible resistance for gas transport.

\section{Concluding Remarks}

Remarkable progress has been made during recent years in nanostructured polymer-based membranes for gas separation applications, particularly for $\mathrm{CO}_{2}$ separations from $\mathrm{H}_{2}, \mathrm{~N}_{2}$ and $\mathrm{CH}_{4}$. Commercial processes based on the nanostructured membranes may emerge soon as potential technologies in gas separation. Improvement on the commercial nanostructured polyamide membranes through interfacial polymerization for desalination by reverse osmosis has been the subject of intensive research, in addition to the continuous effort to synthesize novel membranes which can outperform the polyamide membranes. The nanoscale porous structures and properties of ultrafiltration membranes can be modified by nanoparticles to broaden the use of such membranes.

Although there are many possibilities of nanostructured polymer-based membranes, a careful evaluation on the limitation of each membrane is required such as material availability, cost, ease of processing, compatibility, scale-up prospect, and safety risks associated with nanomaterials. If an extensive study has been done in the preparation and characterization of novel 
nanostructured membranes, then the limitations may be recognized. The future study can then be focused on improving or debottlenecking the current limitations.

\section{Acknowledgements}

The authors would like to thank the National Energy Technology Laboratory of the U. S. Department of Energy and the Nanoscale Science and Engineering Center (NSEC) of the National Science Foundation for the financial support of this work.

\section{References and recommended reading}

Papers of particular interest, published within the period of review, have been highlighted as:

- $\quad$ of special interest

$\bullet \quad$ of outstanding interest

1. ISO/TS 80004-1:2010 ISO Nanotechnologies, Vocabulary, Core Terms. International Organization for Standardization (ISO), Geneva; 2010.

2. Mueller NC, Van der Bruggen B, Keuter V, Luis P, Melin T, Pronk W, Reisewitz R, Rickerby D, Rios GM, Wennekes W, Nowack B: Nanofiltration and nanostructured membranes - Should they be considered nanotechnology or not? J Haz Mater 2012, 211212:275-280.

- This article evaluates the membranes that can be classified as nanostructured membranes based on the ISO definition. Based on the risk associated with the membranes, the authors debated whether all nanostructured membranes are part of nanotechnology and hence called for a need to follow the definitions associated with nanomaterials. 
3. Madaeni SS, Badieh MMS, Vatanpour V, Ghaemi N: Effect of titanium dioxide nanoparticles on polydimethylsiloxane/polyethersulfone composite membranes for gas separation. Polym Eng Sci 2012, 52:2664-2674.

4. Liang CY, Uchytil P, Petrychkovych R, Lai YC, Friess K, Sipek M, Reddy MM, Suen SY: A comparison on gas separation between PES (polyethersulfone)/MMT(Namontmorillonite) and $\mathrm{PES} / \mathrm{TiO}_{2}$ mixed matrix membranes. Sep Purif Technol 2012, 92:57-63.

5. Sun H, Ma C, Yuan B, Wang T, Xu Y, Xue Q, Li P, Kong Y: Cardo polyimides/TiO mixed matrix membranes: Synthesis, characterization, and gas separation property improvement. Sep Purif Technol 2014, 122:367-375.

6. Ahmad J, Hägg MB: Polyvinyl acetate/titanium dioxide nanocomposite membranes for gas separation. J Membr Sci 2013, 445:200-210.

7. Lua AC, Shen Y: Preparation and characterization of polyimide-silica composite membranes and their derived carbon-silica composite membranes for gas separation. Chem Eng J 2013, 220:441-451.

8. Zornoza B, Tellez C, Coronas J: Mixed matrix membranes comprising glassy polymers and dispersed mesoporous silica spheres for gas separation. J Membr Sci 2011, 368:100109.

9. Nafisi V, Hägg MB: Development of nanocomposite membranes containing modified Si nanoparticles in: PEBAX-2533 as a block copolymer and 6FDA-Durene Diamine as a glassy polymer. ACS Appl. Mater. Interfaces 2014, 6:15643-15652.

10. Xing R, Ho WSW: Crosslinked polyvinylalcohol-polysiloxane/fumed silica mixed matrix membranes containing amines for $\mathbf{C O}_{2} / \mathbf{H}_{2}$ separation. J Membr Sci 2011, 367:91-102. 
11. Ismail AF, Rahim NH, Mustafa A, Matsuura T, Ng BC, Abdullah S, Hashemifard SA: Gas separation performance of polyethersulfone/multi-walled carbon nanotubes mixed matrix membranes. Sep Purif Tech 2011, 80:20-31.

12. Ge BL, Zhu Z, Rudolph V: Enhanced gas permeability by fabricating functionalized multi-walled carbon nanotubes and polyethersulfone nanocomposite membrane. Sep Purif Tech 2011, 78:76-82.

13. Deng L, Hägg MB: Carbon nanotube reinforced PVAm/PVA blend FSC nanocomposite membrane for $\mathrm{CO}_{2} / \mathrm{CH}_{4}$ separation. Int J Greenhouse Gas Control 2014, 26:127-134.

14. Zhao Y, Jung BT, Ansaloni L, Ho WSW: Multiwalled carbon nanotube mixed matrix membranes containing amines for high pressure $\mathrm{CO}_{2} / \mathbf{H}_{2}$ separation. J Membr Sci 2014, 459:233-243.

- This paper demonstrated the prospect of multi-walled carbon nanotubes to resolve the membrane compaction phenomenon occurred for high pressure gas separation (1.52 MPa). The stability plots of the membranes were also provided to show the long-term stability of the membrane performance.

15. Li H, Song Z, Zhang X, Huang Y, Li S, Mao Y, Ploehn HJ, Bao Y, Yu M: Ultrathin, Molecular-Sieving Graphene Oxide Membranes for Selective Hydrogen Separation. Science 2013, 342:95-98.

16. Kim HW, Yoon HW, Yoon SM, Yoo BM, Ahn BK, Cho YH, Shin HJ, Yang H, Paik U, Kwon S, Choi JY, Park HB: Selective Gas Transport Through Few-Layered Graphene and Graphene Oxide Membranes. Science 2013, 342:91-94. 
17. Shen J, Liu G, Huang K, Jin W, Lee KR, Xu N: Membranes with Fast and Selective GasTransport Channels Laminar Graphene Oxide for Efficient $\mathbf{C O}_{2}$ Capture. Angew 2015, 127:588-592.

18. Japip S, Wang H, Xiao Y, Chung TS: Highly permeable zeolitic imidazolate framework (ZIF)-71 nano-particles enhanced polyimide membranes for gas separation. $J \mathrm{Membr}$ Sci 2014, 467:162-174.

19. Sorribas S, Zornoza B, Téllez C, Coronas J: Mixed matrix membranes comprising silica(ZIF-8) core-shell spheres with ordered meso-microporosity for natural- and bio-gas upgrading. J Membr Sci 2014, 452:184-192.

20. Li T, Pan Y, Peinemann KV, Lai Z: Carbon dioxide selective mixed matrix composite membrane containing ZIF-7 nano-fillers. J Membr Sci 2013, 425-426:235-242.

21. Nafisi V, Hägg MB: Development of dual layer of ZIF-8/PEBAX-2533 mixed matrix membrane for $\mathrm{CO}_{2}$ capture. J Membr Sci 2014, 459:244-255.

22. Alentiev AY, Bondarenko GN, Kostina YV, Shantarovich VP, Klyamkin SN, Fedin VP, Kovalenko KA, Yampolskii YP: PIM-1/MIL-101 Hybrid Composite Membrane Material: Transport Properties and Free Volume. Petroleum Chem 2014, 54:477-481.

23. Hao L, Zuo J, Chung TS: Formation of Defect-Free Polyetherimide/PIM-1 Hollow Fiber Membranes for Gas Separation. AIChE J 2014, 60:3848-3858.

24. Lau CH, Konstas K, Thornton AW, Liu ACY, Mudie S, Kennedy DF, Howard SC, Hill AJ, Hill MR: Gas-Separation Membranes Loaded with Porous Aromatic Frameworks that Improve with Age. Angew Chem Int Ed 2015, 54:1-6.

25. Qiao Z, Wang Z, Zhang C, Yuan S, Zhu Y, Wang J: PVAm-PIP/PS composite membrane with high performance for $\mathbf{C O}_{2} / \mathbf{N}_{2}$ separation. AIChE J 2013, 59:215-228. 
- This paper described a high performance membrane for $\mathrm{CO}_{2} / \mathrm{N}_{2}$ separation, which was obtained by reducing the membrane thickness to the nanoscale range. The high membrane performance is useful for the post-combustion $\mathrm{CO}_{2}$ capture in coal-fired power plants.

26. Ho WSW, Dutta PK, Schmit, S: Novel inorganic/polymer composite membranes for $\mathrm{CO}_{2}$ capture. 2014 NETL $\mathrm{CO}_{2}$ Capture Technology Meeting, URL: http://www.netl.doe.gov/File\%20Library/Events/2014/2014\%20NETL\%20CO2\%20Capture/

W-Ho-OSU-Inorganic-Polymer-Composite-Membranes.pdf.

- This presentation reported on a novel membrane concept of multilayer structure with nanoscale thicknesses for high-performance $\mathrm{CO}_{2} / \mathrm{N}_{2}$ separation. The high membrane has great potential for the post-combustion $\mathrm{CO}_{2}$ capture in coal-fired power plants.

27. Severance M, Wang B, Ramasubramanian K, Zhao L, Ho WSW, Dutta PK: Rapid crystallization of faujasitic zeolites: mechanism and application to zeolite membrane growth on polymer supports. Langmuir 2014, 30:6929-6937.

28. Ramasubramanian K, Ho WSW: Recent developments on membranes for postcombustion carbon capture. Current Opinion Chem Eng 2011, 1:47-54.

29. Lin H, He Z, Sun Z, Vu J, Ng A, Mohammed M, Kniep J, Merkel TC, Wu T, Lambrecht RC: $\mathrm{CO}_{2}$-selective membranes for hydrogen production and $\mathrm{CO}_{2}$ capture - Part I: Membrane development. J Membr Sci 2014, 457:149-161.

$\bullet$ This work developed thin Polaris ${ }^{\mathrm{TM}}$ membranes (thickness $50-200 \mathrm{~nm}$ ) from lab scale up to a demonstration plant at the National Carbon Capture Center. The membrane showed potential for the pre-combustion $\mathrm{CO}_{2}$ capture in integrated gasification combined cycle (IGCC) power plants.

30. Cadotte, JE: Interfacially synthesized reverse osmosis membrane. U.S. Patent 4,277,344, 1981. 
31. Lau WJ, Ismail AF, Misdan N, Kassim MA: A recent progress in thin film composite membrane: A review. Desalination 2012, 287:190-199.

- This paper reviewed the recent progress in thin-film-composite reverse osmosis membranes, including the effect of aqueous and hydrocarbon solution properties (monomer, surfactant, and additive), application of different substrates, and modified interfacial polymerization for the membrane preparation.

32. Buonomenna MG: Nano-enhanced reverse osmosis membranes. Desalination 2013, 314:73-88.

- This paper reviewed the nano-enhanced reverse osmosis membranes including the inorganic nano-enhanced membranes, thin film nanocomposites, and bio-inspired nano-enhanced membranes.

33. Zhao L, Chang PCY, Ho WSW: High-flux reverse osmosis membranes incorporated with hydrophilic additives for brackish water desalination. Desalination 2013, 308: 225-232.

34. Zhao L, Chang PCY, Yen C, Ho WSW: High-flux and fouling-resistant membranes for brackish water desalination. $J$ Membr Sci 2013, 425-426:1-10.

35. Zhao L, Ho WSW: Novel reverse osmosis membranes incorporated with a hydrophilic additive for seawater desalination. J Membr Sci 2014, 455:44-54.

- This work described the incorporation of the hydrophilic additive into the polyamide membranes and the improvement of water flux and fouling resistance to the organic foulant from seaweed along with the test with real seawater from Port Hueneme, CA.

36. Fathizadeh M, Aroujalian A, Raisi A: Effect of added NaX nano-zeolite into polyamide as a top thin layer of membrane on water flux and salt rejection in a reverse osmosis process. J Membr Sci 2011, 375:88-95. 
37. Pendergast MTM, Ghosh AK, Hoek EMV: Separation performance and interfacial properties of nanocomposite reverse osmosis membranes. Desalination 2013, 308:180185.

38. Humplik T, Lee J, O’Hern SC, Fellman BA, Baig MA, Hassan SF, Atieh MA, Rahman F, Laoui $\mathrm{T}$, Karnik $\mathrm{R}$ et al:: Nanostructured materials for water desalination. Nanotechnology 2011, 22:1-19.

- This article reviewed the nanostructured materials for water desalination including the reverse osmosis membranes based on zeolites, carbon nanotubes, and graphenes.

39. Das R, Ali ME, Hamid SBA, Ramakrishna S, Chowdhury ZZ: Carbon nanotube membranes for water purification: A bright future in water desalination. Desalination 2014, 336:97-109.

- This paper reviewed the potential of carbon nanotubes in water desalination, including the study of water transport in carbon nanotubes, fabrication and functionalization of carbon nanotubes, carbon nanotube membranes quality control, and comparison to the other conventional membranes.

40. Du F, Qu L, Xia Z, Feng L, Dai L: Membranes of vertically aligned superlong carbon nanotubes. Langmuir 2011, 27:8437-8443.

41. Zhang L, Shi GZ, Qiu S, Cheng LH, Chen HL: Preparation of high-flux thin film nanocomposite reverse osmosis membranes by incorporating functionalized multiwalled carbon nanotubes. Desalination and Water Treatment 2011, 34:19-24.

42. Choi W, Choi J, Bang J, Lee JH: Layer-by-layer assembly of graphene oxide nanosheets on polyamide membranes for durable reverse-osmosis applications. ACS Appl. Mater. Interfaces 2014, 5:12510-12519. 
43. Kim SG, Hyeon DH, Chun JH, Chun BH, Kim SH: Nanocomposite poly(arylene ether sulfone) reverse osmosis membrane containing functional zeolite nanoparticles for seawater desalination. $J$ Membr Sci 2013, 443:10-18.

44. Akin I, Zor E, Bingol H, Ersoz M: Green synthesis of reduced graphene oxide/polyaniline composite and its application for salt rejection by polysulfone-based composite membranes. J Phys Chem B 2014, 118:5707-5716.

45. Ho WSW, Sirkar KK (Eds): Membrane Handbook. Chapman \& Hall; 1992;

Ho WSW, Sirkar KK (Eds): Membrane Handbook. Kluwer Academic Publishers; 2001.

46. Lai CY, Groth A, Gray S, Duke M: Nanocomposites for improved physical durability of porous PVDF membranes. Membranes 2014, 4:55-78.

- This paper reviewed the development of nanocomposite PVDF membranes for water treatment application, including the evaluation of the effects of nanofillers such as nanoparticles, carbon nanotubes, and nanoclays on water flux, fouling resistance, mechanical strength, and abrasion resistance.

47. Hong J, He Y: Polyvinylidene fluoride ultrafiltration membrane blended with nano-ZnO particle for photo-catalysis self-cleaning. Desalination 2014, 332:67-75.

48. Jin Y, Hua Y, Zhang P, Yun Y, Zhang P, Li C: Preparation and characterization of poly (vinylidene fluoride) ultrafiltration membrane with organic and inorganic porogens. Desalination 2014, 336:1-7.

49. Yi XS, Yu SL, Shi WX, Wang S, Sun N, Jin LM, Ma C: Estimation of fouling stages in separation of oil/water emulsion using nano-particles $\mathrm{Al}_{2} \mathrm{O}_{3} / \mathrm{TiO}_{2}$ modified PVDF UF membranes. Desalination 2013, 319:38-46. 
50. Guillen GR, Pan Y, Li M, Hoek EMV: Preparation and characterization of membranes formed by nonsolvent induced phase separation: a review. Ind Eng Chem Res 2011, 50:3798-3817.

- This article reviewed the influences of various parameters (choice of solvent, polymer, polymer concentration, nonsolvent, and additives) during the preparation of membranes by nonsolvent induced phase separation and the methods which could be used to characterize the membranes.

51. Alhoshan M, Alam J, Dass LA, Al-Homaidi N: Fabrication of polysulfone/ZnO membrane: influence of $\mathrm{ZnO}$ nanoparticles on membrane characteristics. Adv Polym Tech 2013, 32:21369(1-7).

52. $\mathrm{Wu} \mathrm{H}$, Tang $\mathrm{B}$, Wu $\mathrm{P}$ : Development of novel $\mathrm{SiO}_{2}-\mathbf{G O}$ nanohybrid/polysulfone membrane with enhanced performance. J Membr Sci 2014, 451:94-102.

53. Liu F, Ma BR, Zhou D, Xiang YH, Xue LX: Breaking through tradeoff of polysulfone ultrafiltration membranes by zeolite 4A. Microporous Mesoporous Mater 2014, 18:113120.

54. Zhao C, Xue J, Ran F, Sun S: Modification of polyethersulfone membranes - A review of methods. Prog Mater Sci 2013, 58:76-150.

- This paper reviewed the methods that can be used to modify PES membranes, including bulk modification, blending method, surface coating, photo-induced, gamma ray-induced, plasmainduced, and thermal-induced grafting.

55. Lin J, Zhang R, Ye W, Jullok N, Sotto A, Van der Bruggen B: Nano-WS $\mathbf{2}$ embedded PES membrane with improved fouling and permselectivity. J Colloid Interface Sci 2013, 396:120-128. 
56. Kim J, Sotto A, Chang J, Nam D, Boromand D, Van der Bruggen B: Embedding $\mathbf{T i O}_{2}$ nanoparticles versus surface coating by layer-by-layer deposition on nanoporous polymeric films. Microporous Mesoporous Mater 2013, 173:121-128.

57. Akar N, Asar B, Dizge N, Koyuncu I: Investigation of characterization and biofouling properties of PES membrane containing selenium and copper nanoparticles. $J \mathrm{Membr}$ Sci 2013, 437:216-226.

58. Lalia BS, Kochkodan V, Hashaikeh R, Hilal N: A review on membrane fabrication: Structure, properties and performance relationship. Desalination 2013, 326:77-95.

- This paper reviewed the methods that can be used to prepare membranes and the relationships between structure, property and performance of the membranes including the crystallinity, pore structure, surface charge, and surface roughness.

59. Yen C, He H, Lee LJ, Ho WSW: Synthesis and characterization of nanoporous polycaprolactone membranes via thermally- and nonsolvent-induced phase separations for biomedical device application. J Membr Sci 2009, 343:180-188.

60. Yen C, He H, Fei Z, Zhang X, Lee LJ, Ho WSW: Surface modification of nanoporous poly(e-caprolactone) membrane with poly(ethylene glycol) to prevent biofouling: Part I. effects of plasma power and treatment time. Int J Polym Mater 2010, 59:923-942.

61. Yen C, He H, Fei Z, Zhang X, Lee LJ, Ho WSW: Surface modification of nanoporous poly(E-caprolactone) membrane with poly(ethylene glycol) to prevent biofouling: Part II. effects of graft density and chain length. Int J Polym Mater 2010, 59:943-957.

62. Vilt ME, Ho WSW: Supported liquid membranes with strip dispersion for the recovery of Cephalexin. J Membr Sci 2009, 342:80-87. 
63. Vilt ME, Ho WSW: Selective separation of Cephalexin from multiple component mixtures. Ind Eng Chem Res 2010, 49:12022-12030.

64. Vilt ME, Ho WSW: In situ removal of Cephalexin by supported liquid membrane with strip dispersion. J Membr Sci 2011, 367:71-77.

65. Hao Z, Vilt ME, Wang Z, Zhang W, Ho WSW: Supported liquid membranes with feed dispersion for recovery of Cephalexin. J Membr Sci 2014, 468:423-431.

66. Hao Z, Wang Z, Zhang W, Ho WSW: Supported liquid membranes with organic dispersion for recovery of Cephalexin. J Membr Sci 2014, 468:90-97.

67. Ho WSW, Dutta PK, Schmit, S: Novel inorganic/polymer composite membranes for $\mathrm{CO}_{2}$ capture. FE0007632 Project Continuation Application Meeting, URL: http://www.netl.doe.gov/File\%20Library/Research/Coal/carbon\%20capture/postcombustion/FE0007632-Continuation-Application-Status-Mtg-public-release-8-11-14.pdf. 